\title{
Addressing Sexual Minority Issues in Social Work Education: A Curriculum Framework
}

\author{
Lindsay Gezinski
}

\begin{abstract}
This paper will explore a curriculum framework that explicitly addresses the reduction of heterosexism as a means to produce students that are culturally competent to practice with the lesbian, gay, bisexual, transgender, and queer (LGBTQ) community. Van Den Bergh and Crisp (2004) place great importance on addressing beliefs/attitudes, knowledge, and skills when broaching culturally competent practice with the LGBTQ population. Beliefs/attitudes, knowledge, and skills in an educational approach will be advocated in this paper. Specifically, the creation of a constructivist environment will be endorsed as a means for students to critically assess their own beliefs/attitudes, knowledge, and skills. A curriculum framework that utilizes classroom activities related to heterosexual privilege, policy, and practice role plays will be discussed. This curriculum framework is intended to prepare social work students to work with LGBTQ clients.
\end{abstract}

Keywords: LGBTQ, social work, curriculum, constructivism, heterosexism

\section{INTRODUCTION}

The sexual identities of lesbian, gay, bisexual, transgender, and queer (LGBTQ) represent a risk factor within the context of social work practice (Van Den Bergh \& Crisp, 2004). However, LGBTQ issues are not sufficiently included in social work education (Mackelprang, Ray \& Hernandez-Peck, 1996). Therefore, this paper will develop a culturally competent curriculum framework to prepare social work students to work with LGBTQ clients. Emphasis will be placed on the acquisition of critical thinking skills in a constructivist learning environment.

\section{LITERATURE REVIEW}

Cultural competence is the end result of a process requiring one's attempt to recognize and understand another's culture (Van Den Bergh \& Crisp, 2004). The Council on Social Work Education (CSWE)'s accreditation guidelines for schools of social work address diversity in the learning environment, as well as diversity in practice. Accreditation Standard 3.1.1 states that the social work program "describes the specific and continuous efforts it makes to provide a learning environment in which respect for all persons and understanding of diversity and difference are practiced" (Council on Social Work Education [CSWE], 2008, p. 11). Further, the program and curriculum are expected to understand and respect diversity.

The National Association of Social Workers (NASW) (2001) Standards for Cultural Competence in Social Work Practice emphasize the importance of self-awareness of

Lindsay Gezinski is a Ph.D. student at The Ohio State University, College of Social Work.

Copyright (C) 2009 Advances in Social Work Vol. 10 No. 1 (Spring 2009), 103-113 
one's values and beliefs, as well as knowledge and skills of cultures that are different from one's own. The aforementioned guidelines and standards serve as a framework for the evaluation of social work programs to determine if curriculum is inclusive of LGBTQ issues.

The likelihood is high that social work students will interact with LGBTQ clients at some point during the course of their careers (Mackelprang et al., 1996); however, colleges of social work often fail to incorporate LGBTQ material in programs of study (Hylton, 2005). This lack of inclusion may be a result of the fact that sexual orientation is consistently ranked as being less important than race, ethnicity, and gender (Mackelprang et al., 1996). The inclusion of LGBTQ issues in curriculum is necessary due to rates of homophobia among social work practitioners and students. While Berkman and Zinberg (1997) found that 10.7 percent of social workers holding a MSW are low-grade homophobic, Wisniewski and Toomey (1987) found that one-third of social workers are homophobic. MSW students were found to be more tolerant than existing social work practitioners (Newman, Dannenfelser \& Benishek, 2002), which may indicate that the field is becoming increasingly tolerant and accepting of sexual minorities.

While several of the previously mentioned studies indicate relatively low homophobia in the field of social work, one must also consider the construct of heterosexism. Morrow (1996) defines heterosexism "as the promotion and valuing of heterosexuality over nonheterosexuality. Heterosexism systematically privileges those who have a heterosexual identity while simultaneously oppressing those who have a gay, lesbian, or bisexual identity” (p. 2). Raiz and Saltburg (2007) found that 21.3 percent of BSSW students were non-accepting of lesbians and gay men, while 40.0 percent of BSSW students were found to be tolerant with conditions. The 'tolerant with conditions' subgroup was found to conceive this population in a heterosexist manner. Thus, many participants held heterosexuality as the norm.

This paper will explore a curriculum framework that explicitly addresses the reduction of heterosexism as a means to produce students that are culturally competent of the LGBTQ community. Van Den Bergh and Crisp (2004) place great importance on addressing beliefs/attitudes, knowledge, and skills when broaching culturally competent practice with the LGBTQ population. Beliefs/attitudes, knowledge, and skills in an educational approach will be advocated in this paper. Specifically, the creation of a constructivist environment will be endorsed as a means for students to critically assess their own beliefs/attitudes, knowledge, and skills.

\section{CURRICULUM FRAMEWORK}

A holistic approach that examines the macro/micro, theoretical/practical is necessary in the inclusion of LGBTQ material in social work curriculum. Although schools of social work may offer courses with a focus on LGBTQ issues, the infusion of LGBTQ material into all social work coursework is necessary. This relies on the belief that LGBTQ oppression cannot be viewed separate from other oppressions (e.g., race/ethnicity, sex, physical ability, class, etc.) due to the intersectionality of individuals.

Intersectionality realizes the social stratification of people, meaning that the combination 
of one's race/ethnicity, sex, physical ability, class, sexual orientation, and gender identity intersect resulting in unique experiences (Collins, 2000). For example, in contrast to white gay men, black lesbians are forced to contend with heterosexism and racism and sexism. The endorsement of within group differences is extremely important when discussing LGBTQ material with students. However, the creation of binaries is potentially dangerous resulting in an object/subject dichotomy (McPhail, 2004). The creation of a constructivist environment that fosters and nurtures students' critical thinking skills may contribute to the rejection of such binaries that create sexual minorities as "other".

\section{Setting the Stage-Creating a Constructivist Space for Critical Thinking}

The effectiveness of engaging with students in a dialogue about sexuality and gender identity will rest on the environment of the larger community, college, and classroom. Prior to the first day of class, the instructor may choose to assess the context of the larger community and the college. Questions may include the following:

- Is the college or school located in a rural or urban area? Rural areas have been found to contribute to higher sexual prejudice towards homosexuals (Herek, 2002; Wills \& Crawford, 2000).

- Does religion figure prominently in the community and in the college? Identification as Protestant or Catholic is associated with negative anticipated professional behavior with lesbian clients (Cramer, 1997).

- What is the racial breakdown of the community and school? Some studies have shown that blacks hold more negative attitudes towards homosexuality than whites (Lewis, 2003), while others indicate that whites hold more negative attitudes (Levitt \& Klassen, 1974).

- Do the community and college favor conservative or liberal ideology? Conservatism has been found to be associated with greater homophobia when compared to liberalism (Snively, Krueger, Stretch, Watt \& Chadha, 2004).

Answers to these questions may offer important information related to teaching approaches. For example, students attending schools of social work in rural areas that are highly conservative and religious may be resistant to LGBTQ material. Thus, a great amount of attention may be placed on attitudes/beliefs prior to addressing knowledge and skills. In contrast, social work students in urban areas that are highly liberal may be more receptive to such material. Therefore, emphasis may be placed on knowledge acquisition and skills rather than attitudes/beliefs. It is important to consider whether or not students are bred inside or outside of the community surrounding the college. The aforementioned assessment may be more pertinent for students bred in the surrounding community. However, some students may originate from communities quite different than the one surrounding the college. 
The creation of a constructivist classroom that acts as a safe space is of utmost importance to student learning. Brooks and Brooks (1993) describe a constructivist classroom in contrast to a traditional classroom (p. 17) as follows:

\section{Traditional Classroom}

Curriculum is presented part to whole, with emphasis on basic skills.

Strict adherence to fixed curriculum is highly valued.

Students are viewed as “blank slates”' onto which information is "etched" by the teacher.

Teachers generally behave in a didactic manner, disseminating information to students.

Teachers seek the correct answer to validate student learning.

Assessment of student learning is viewed as separate from teaching and occurs almost entirely through testing.

\section{Constructivist Classroom}

Curriculum is presented whole to part with emphasis on big concepts.

Pursuit of student questions is highly valued.

Students are viewed as thinkers with emerging theories about the world.

Teachers generally behave in an interactive manner, mediating the environment for students.

Teachers seek the students' point of view in order to understand students' present conceptions for use in subsequent lessons.

Assessment of student learning is interwoven with teaching and occurs through teacher observations of students at work and through personalized assignments.

Piaget is often considered to be the founder of constructivism. He held that reality is not concrete. Instead, individual realities are constantly changing as a result of time and new experiences (Piaget, 1970). A constructivist environment is the result of teamwork and support on the part of the instructor and students in an effort to analyze one's own beliefs and the beliefs of others (Nichols-Casebolt, Figueira-McDonough \& Netting, 2000). Discourse is constructive when students are active participants in their own learning and the learning of others. The instructor may facilitate this type of environment through denying ideas as factual and concrete and rather as fluid and open to interpretation. Additionally, it is the instructor's responsibility to act as a model for challenging her/his own beliefs and those of the students. Through modeling the instructor, students may feel greater comfort in challenging beliefs and attitudes.

This type of environment is conducive to the endorsement of critical thinking. Critical thinking relies on the notion that knowledge is socially constructed and requires students to be reflexive considering strengths, weaknesses, and underlying notions of arguments (Gibbons \& Gray, 2004). A guiding question for conversation may be "How do we know what we know?" This simple question relates to the social-historical construction of knowing and may act as a catalyst for deep analysis of the origins of beliefs/attitudes regarding power dynamics on multiple levels. 
This constructivist environment of critical thinking is likely to be most effective in a classroom that acts as a safe space. A safe space is defined as "a classroom climate that allows students to feel secure enough to take risks, honestly express their views, and share and explore their knowledge, attitudes, and behaviors" (Holley \& Steiner, 2005, p. 50). The space is safe when students know that they will not face criticisms as a result of sharing their ideas (Boostrom, 1998). Rather than prohibit conflict amongst students, it should be the responsibility of the instructor to manage conflict (Osborne, 1997). Holley and Steiner (2005) found that the creation of a safe space results in students' increased learning and self-examination of beliefs. This safe space results in free expression, which may result in the discomfort of some students. The instructor may choose to devise a policy that balances this freedom of expression with a stance of non-discrimination.

While the aforementioned strategies for inclusion of material are relatively abstract, tangible strategies are also available. For instance, the random assignment of students to small groups for the length of the course may allow students to become acquainted with others that are unlike themselves resulting in relationship-building and a sense of community offering opportunities for empowerment (Dore, 1997). Students that openly identify as LGBTQ may positively impact group members. Research indicates that homophobic attitudes are reduced when an individual has contact with a gay man or lesbian (Berkman \& Zinberg, 1997). This process of creating a constructive atmosphere conducive to free thought sets the stage for challenging beliefs/attitudes.

\section{Challenging Beliefs/Attitudes—The Power Dynamics of Institutionalized Heterosexism}

The discussion of power differentials and the "mythical norm” (Lorde, 1984) may serve as a backdrop for continued conversations of oppression, such as institutionalized heterosexism. Lorde (1984) describes the "mythical norm" and states, "In America, this norm is usually defined as white, thin, male, young, heterosexual, Christian, and financially secure. It is with this mythical norm that the trappings of power reside within society" (p. 116). Thus, this "mythical norm" serves to define those that do not fall into these categories as the "other." Students could be asked to reflect on this notion of the "mythical norm" and discuss its implications. For instance, students could describe their own "otherness" and how this "otherness" fosters various forms of oppression, including institutionalized heterosexism.

Students could be requested to describe the ways in which social welfare policy perpetuates institutionalized heterosexism. For example, the underlying notion of heteronormativity found in Temporary Assistance for Needy Families (TANF) could be analyzed (Fineman, Mink \& Smith, 2003). Students could be requested to describe the ways in which this promotion of marriage and two-parent families relies on the presumption of heterosexuality. Further, discussion could reflect on the ways this presumed heterosexuality results in the invisibility of the LGBTQ population.

A discussion of heterosexual privilege would nicely complement this discussion of institutionalized oppression. McIntosh (1990) describes the privileges associated with being white, which include the following: 
"If I should need to move, I can be pretty sure of renting or purchasing housing in an area that I can afford and in which I would want to live.”

"I can go shopping alone most of the time, pretty well assured that I will not be followed or harassed."

Students could be assigned McIntosh's (1990) article and requested to identify heterosexual privileges. The LGBT Resource Center at University of Missouri-Columbia (2008) exemplifies heterosexual privileges with the following statements:

"If you are heterosexual (or, in some cases, simply perceived as heterosexual), you can go wherever you want and know that you will not be harassed, beaten, or killed because of your sexuality (16 people were known to be murdered in 2000 because of being perceived as gay, 29 were killed in 1999, and 26 in 1998).”

"If you are heterosexual (or, in some cases, simply perceived as heterosexual), you can raise, adopt, and teach children without people believing that you will molest them or force them in to your sexuality. Moreover, people generally will not try to take away your children because of your sexuality."

A discussion of institutionalized heterosexism could be followed by a self-assessment of students' own homophobia and heterosexism. The use of a pre- and post-test may represent a useful tool for students to gauge their own levels of homophobia and heterosexism. The following represent reliable instruments for this task: Attitudes toward Lesbians and Gay Men Scale (Herek, 1988) and Index of Attitudes towards Homophobia (Wisniewski \& Toomey, 1987). Following the students' initial self-assessment, the instructor could facilitate a discussion requesting students to reflect on their understanding and perceptions of homophobia and heterosexism. Students could again complete the self-assessment at the conclusion of the course. Resultant discussion could revolve around changes in attitudes or lack thereof over the course of the class.

\section{Building Knowledge-Theory and Practice}

The acquisition of knowledge regarding LGBTQ issues can be framed in theoretical and practical terms. In Human Behavior and the Social Environment (HBSE) courses, theories of development can be viewed as they apply to sexual minorities (Van Den Bergh \& Crisp, 2004). For instance Cass' (1984) model of gay and lesbian identity formation could be examined in combination with Erikson's $(1950 ; 1959)$ stages of psychosocial development. Identity confusion, identity comparison, identity tolerance, identity acceptance, identity pride, and identity synthesis are associated with gay and lesbian identity formation (Cass, 1984). Additionally, theories may be examined as to how they affect sexual minority populations in contrast to other populations.

Regarding practice, knowledge is needed around appropriate terminology, coming out, familial relationships, and so on (Morrow, 1996). Further, students should become acquainted with community resources and social service networks that specifically address the LGBTQ population, as well as effective methods for advocacy work (Mackelprang et al., 1996; Van Den Bergh \& Crisp, 2004). Videos, guest speakers, and 
journal articles represent various methods for knowledge acquisition regarding minority populations (Colvin-Burque, Zugazaga \& Davis-Maye, 2007). Various journal articles may be helpful in incorporating LGBTQ issues in mental health, health, aging, youth, families, and so on. (See Berger, 1984; Gomez \& Smith, 1990; Laird, 1994; Levy, 1995; Marsiglia, 1998; Parks, 2001).

\section{Teaching Skills for Practice}

Vignettes and role-plays represent mediums in which to practice clinical skills (Cramer, 1997; Van Den Bergh \& Crisp, 2004). The following represent potential roleplays for classroom activity.

Role play 1. You are a school social worker in a rural area. Charlotte, once a straight ' $A$ ' student, has experienced a sharp decline in grades and class participation. Charlotte tells you that she has been thrown out of her household following "coming out" to her parents. She currently has no communication with her parents and is residing on friends' couches.

For role play 1 , students could be encouraged to examine the ways in which Charlotte's sexual orientation interacts with her school and home life. Issues for special consideration include: school, family, homelessness, child welfare, and so on. Cass' (1984) model of gay and lesbian identity formation could be discussed in relation to adolescent development. Further, exploration of housing issues, social support networks for LGBTQ youth, and community resources provide a starting point for discussing the impact of lesbian-identification on youth.

Role play 2. You are a hospital social worker. Darrell has been hospitalized following a stroke and remains in a coma. His partner of forty years, Michael, is being refused access to Darrell by hospital staff because they state that he is not a relative.

For role play 2, students could be asked to reflect on the implications of policy and the ways in which marriage affects gay and lesbian rights. Further, students may be requested to explore effective ways for navigating the bureaucracy of the hospital system. Special issues for consideration include grief and bereavement, as well as family systems. It may be important for the student to consider the quality of the relationship that exists between Michael and the rest of Darrell's family. Are they accepting and supportive of Darrell and Michael's relationship? Further, access to resources may be addressed. For instance, Michael may not have access to Darrell's assets despite their lengthy cohabitation.

Role play 3. Leslie, born Joel, presents at your office due to depression and cocaine abuse. Leslie states that she hopes soon to transition fully from male to female. She claims that her mental health and substance abuse issues will diminish following transition.

For role play 3, students may be asked to consider Leslie's mental health and substance abuse issues. Further, special consideration should be placed on Leslie's 
transition process, including key terminology and stages of transition. The student may choose to assess Leslie's claim that her depression and cocaine abuse will cease to exist following transition. Further, a discussion could ensue around community resources and social support networks for transgendered individuals. Finally, a discussion could commence regarding the ways in which the Diagnostic and Statistical Manual of Mental Disorders (DSM) pathologizes transgendered individuals with the classification of Gender Identity Disorder.

\section{FUTURE RESEARCH}

Although a curricular framework has been presented here, its level of effectiveness is unknown. Research is needed that examines the reliability and validity of this approach through the utilization of a quasi-experimental design. Research questions may include the following:

- Do social work students experience a change in their attitudes/beliefs, because of increased coverage of LGBTQ issues in social work curriculum? Specifically, do homophobia and heterosexism decrease as a result of LGBTQ-inclusive curriculum?

- Do social work students gain knowledge regarding the LGBTQ community, because of exposure to LGBTQ issues in social work curriculum? Specifically, do students gain knowledge of theories of development, terminology, community resources, etc.?

- Do social work students gain effective skills for practice with LGBTQ clients as a result of LGBTQ-inclusive curriculum? Specifically, are social work practitioners able to effectively interact with LGBTQ clients as a result of LGBTQ-inclusive curriculum?

\section{CONCLUDING REMARKS}

A culturally competent curriculum framework is necessary to prepare social work students to work with LGBTQ clients. A constructive, "safe space" is essential for the development of students' critical thinking skills. These critical thinking skills will allow students to analyze their own attitudes/beliefs regarding oppressions, including institutionalized heterosexism. Through the dispersal of diverse knowledge and skills, schools of social work will likely produce culturally competent social work practitioners.

\section{References}

Berger, R. M. (1984). Realities of gay and lesbian aging. Social Work, 29, 57-62.

Berkman, C. S., \& Zinberg, G. (1997). Homophobia and heterosexism in social workers. Social Work, 42(4), 319-332.

Boostrom, R. (1998). 'Safe spaces': Reflections on an educational metaphor. Journal of Curriculum Studies, 30(4), 397-408. 
Brooks, J. G., \& Brooks, M. G. (1993). In search of understanding: The case for constructivist classrooms. Alexandria, VA: Association for Supervision and Curriculum Development.

Cass, V. C. (1984). Homosexual identity formation: Testing a theoretical model. The Journal of Sex Research, 20(2), 143-167.

Collins, P. H. (2000). Black feminist thought ( $2^{\text {nd }}$ ed.). New York: Routledge.

Colvin-Burque, A., Zugazaga, C. B, \& Davis-Maye, D. (2007). Can cultural competence be taught? Evaluating the impact of the SOAP Model. Journal of Social Work Education, 43(2), 223-241.

Council on Social Work Education. (2008). Educational policy and accreditation standards. Retrieved March 30, 2009 from http://www.cswe.org/NR/rdonlyres/2A81732E-1776-4175-AC42 65974E96BE66/0/2008EducationalPolicyandAccreditationStandards.pdf.

Cramer, E. P. (1997). Effects of an educational unit about lesbian identity development and disclosure in a social work methods course. Journal of Social Work Education, 33(3), 461-472.

Dore, M. M. (1997). Feminist pedagogy and the teaching of social work practice. Journal of Social Work Education, 30(1), 97-106.

Erikson, E. H. (1950). Childhood and society. New York: Norton.

Erikson, E. H. (1959). Identity and the life cycle. New York: International Universities Press.

Fineman, M., Mink, G., \& Smith, A. M. (2003). No promotion of marriage in TANF! Social Justice, 30(4), 126-134.

Gibbons, J., \& Gray, M. (2004). Critical thinking as integral to social work practice. Journal of Teaching in Social Work, 24(1/2), 19-38.

Gomez, J., \& Smith, B. (1990). Taking the home out of homophobia: Black lesbian health. In. E. C. White (Ed.), The black women's health book: Speaking for ourselves (pp. 198-213). Seattle, WA: The Soul Press.

Herek, G. (1988). Heterosexuals' attitudes toward lesbians and gay men: Correlates and gender differences. Journal of Sex Research, 25, 451-477.

Herek, G. M. (2002). Heterosexuals' attitudes toward bisexual men and women in the United States. Journal of Sex Research, 39 (4), 264-274.

Holley, L. C., \& Steiner, S. (2005). Safe space: Student perspectives on classroom environment. Journal of Social Work Education, 41(1), 49-64.

Hylton, M. E. (2005). Heteronormativity and the experiences of lesbian and bisexual women as social work students. Journal of Social Work Education, 41(1), 67-82. 
Laird, J. (1994). Lesbian families: A cultural perspective. Smith College Studies in Social Work, 64 (3), 263-296.

Levy, E. (1995). Feminist social work practice with lesbian and gay clients. In N. Van Den Bergh (Ed.), Feminist practice in the 21st century (Chapter 15, pp. 278-294). Washington, DC: NASW Press.

Levitt, E. E., \& Klassen, A. D. (1974). Public attitudes toward homosexuality: Part of the 1970 national survey by the Institute for Sex Research. Journal of Homosexuality 1(1), 29-43.

Lewis, G. B. (2003). Black-white differences in attitudes toward homosexuality and gay rights. Public Opinion Quarterly, 67, 59-78.

Lorde, A. (1984). Sister outsider: Essays and speeches. Berkeley, CA: The Crossing Press.

Mackelprang, R. W., Ray, J., \& Hernandez-Peck, M. (1996). Social work education and sexual orientation: Faculty, student, and curriculum issues. Journal of Gay \& Lesbian Social Services, 5(4), 17-31.

Marsiglia, F. F. (1998). Homosexuality and Latinos/as: Towards an integration of identities. Journal of Gay and Lesbian Social Services, 8(3), 113-125.

McIntosh, P. (1990). White privilege: Unpacking the invisible knapsack. Independent School, 49(2), 31-35.

McPhail, B. A. (2004). Questioning gender and sexuality binaries: What queer theorists, transgendered individuals, and sex researchers can teach social work. Journal of Gay \& Lesbian Social Services, 17(1), 3-21.

Morrow, D. F. (1996). Heterosexism: Hidden discrimination in social work education. Journal of Gay \& Lesbian Social Services, 5(4), 1-16.

National Association of Social Workers National Committee on Racial and Ethnic Diversity. (2001). NASW standards for cultural competence in the practice of social work. Washington, DC: Author.

Newman, B. S., Dannenfelser, P. L., \& Benishek, L. (2002). Assessing beginning social work and counseling students' acceptance of lesbians and gay men. Journal of Social Work Education, 38(2), 273-288.

Nichols-Casebolt, A., Figueira-McDonough, J., \& Netting, F. E. (2000). Change strategies for integrating women's knowledge into social work curricula. Journal of Social Work Education, 36(1), 65-78

Osborne, M. D. (1997). Balancing individual and the group: A dilemma for the constructivist teacher. Journal of Curriculum Studies, 29(2), 183-196.

Parks, C. W. (2001). African-American same-gender-loving youths and families in urban schools. Journal of Gay \& Lesbian Social Services, 13(3), 41-56.

Piaget, J. (1970). Logic and psychology (W. Mays, Trans.). New York: Basic Books. 
Raiz, L., \& Saltzburg, S. (2007). Developing awareness of the subtleties of heterosexism and homophobia among undergraduate, heterosexual social work majors. The Journal of Baccalaureate Social Work, 12(2), 53-69.

Snively, C. A., Kreuger, L., Stretch, J. J., Watt, J. W., \& Chadha, J. (2004). Understanding homophobia: Preparing for practice realities in urban and rural settings. Journal of Gay \& Lesbian Social Services, 17(1), 59-81.

University of Missouri-Columbia LGBT Resource Center. (2008). What is heterosexual privilege? Retrieved on March 8, 2008 from http://web.missouri.edu/ umcstudentlifelgbt/resources/heterosexualprivilegeintro.pdf

Van Den Bergh, N., \& Crisp, C. (2004). Defining culturally competent practice with sexual minorities: Implications for social work education and practice. Journal of Social Work Education, 40(2), 221-238.

Wills, G., \& Crawford, C. (2000). Attitudes toward homosexuality in Shreveport-Bossier City Louisiana. Journal of Homosexuality, 38, 97-115.

Wisniewski, J. J., \& Toomey, B. G. (1987). Are social workers homophobic? Social Work, 32(5), 454-455.

\section{Author's note:}

Address correspondence to: Lindsay Gezinski, MSW, M.A., College of Social Work, The Ohio State University, 1947 College Road, Columbus, Ohio 43210. Email:

lgezinski@yahoo.com 